\title{
SELF-REGULATED LEARNING IN WEB-BASED ENVIRONMENTS: INSTRUCTIONAL TOOLS DESIGNED TO FACILITATE COGNITIVE STRATEGY USE, METACOGNITIVE PROCESSING, AND MOTIVATIONAL BELIEFS*
}

\author{
DOUGLAS F. KAUFFMAN \\ University of Oklahoma
}

\begin{abstract}
This study investigated strategies teachers can use to improve students' use of self-regulated learning strategies in a Web-based setting. SRL is defined as a learner's intentional efforts to manage and direct complex learning activities and is composed of three primary components including cognitive strategy use, metacognitive processing, and motivational beliefs. These three components are defined relative to note-taking methods (cognitive component), self-monitoring prompts (metacognitive component), and self-efficacy buildng feedback (motivation component). One hundred nineteen students were assigned randomly to one cell in a $2 \times 2 \times 2$ design. Students took notes in a matrix or a free form method from a Web site about educational measurement and either received or did not receive self-monitoring prompts and self-efficacy building feedback. Results indicated note-taking method had the strongest influence on both the amount of information gathered and achievement. Additionally, both academic self-efficacy building feedback and self-monitoring prompts demonstrated modest effects on achievement. Results are discussed relative to SRL theory, classroom application, and Web-based instructional design.
\end{abstract}

*This research was funded by a grant from Star Schools of the Department of Education Grant \# R203D6003. A version of this manuscript was presented at the 2002 annual meeting of the American Educational Research Association, New Orleans, Louisiana. 
Educational researchers have identified cognitive strategy use, motivation, and metacognitive processing as hallmarks of academic success (e.g., Butler \& Winne, 1995; Perry, 2002; Pintrich, 2000; Schraw, Kauffman, \& Lehman, 2002; Zimmerman, 1989, 1994). For example, effective learners regularly take complete and organized sets of notes (cognitive strategy use), possess high levels of academic self-efficacy (motivation), and monitor their progress on various academic tasks (metacognition) (e.g., Horn, Bruning, Schraw, \& Curry, 1993). In short, academically successful students are self-regulated. Unfortunately, not all students are self-regulated. Many fail to use cognitive strategies, are unmotivated, or do not self monitor. This may be particularly relevant in Web-based environments where students are often asked to complete complex academic tasks with little or no support from classmates or teachers.

Intuitively, Web-based instruction seems to be an ideal learning environment. Students have access to an almost unlimited amount of information they can use in multiple ways. Additionally, students can access information at their convenience, are free to work at their own pace, and can revisit information they find confusing and/or interesting (Lehman, Kauffinan, White, Horn, \& Bruning, 2001). The nature of many Web-based instructional tasks, however, involves independent learning that requires students to be highly self-regulated. Accordingly, students - particularly those who are less self-regulated - may benefit from prompts that encourage cognitive strategy use, motivation, and metacognitive processing.

\section{WHAT IS SELF-REGULATION}

Researchers seem to agree that self-regulation is a general construct that can explain multiple areas of human functioning (e.g., Bandura, Barbaranelli, Caprara, \& Pasterelli, 1996). The present study examines self-regulated learning (SRL), which involves learners' intentional efforts to manage and direct complex learning activities (DuBois \& Staley, 1997; Winne, 1995). From this perspective, SRL is a multidimensional construct that includes complex interactions among cognitive strategy use, motivation, and metacognition (Butler \& Winne, 1995; Perry, 2002; Schraw et al., 2002; Zimmerman, 2000).

Much of the educational research conducted over the past 10-15 years has explored cognitive, motivational, or metacognitive strategy use either in isolation or along with one other component. Surprisingly few studies have investigated how all three components work together. Hattie, Biggs, and Purdie (1996), for example, concluded that the field of educational psychology lacked empirical research exploring how motivation and metacognition influence students' use of study skills. According to these researchers ". . . theory may have leaped ahead of the evidence" (p. 103). The present study was an initial attempt to bridge the gap between theory and practice by exploring how cognitive strategy, metacognitive, 
and motivational prompts embedded into a Web-based instructional module influence students' achievement.

\section{Cognitive Strategy Component}

Self-regulated learning's cognitive strategy component includes activities that support students' active manipulation of academic content. Most describe this in terms of learning strategies, which include any cognitive operations over and above the processes related directly to carrying out a task (Pressley et al., 1995). In the present study, the cognitive strategy component was operationalized as note taking methods. Students were prompted to take notes using either a traditional free form approach or using a matrix organizer.

Note taking researchers generally define free form note taking as a baseline approach, or what students do before learning more effective methods. In most cases, free form notes involve recording one fact after another in an almost list-like fashion (Kiewra, 1985; Kiewra et al., 1991) (see Figure 1). A matrix organizer, in contrast, is a two-dimensional cross-classification table with topics along the top row, repeatable categories down the left-most column, and details in the intersecting cells (Kauffman \& Kiewra, 1999; Kauffman, Lebow, Kiewra, \& Igo, 2000). An example matrix organizer appears in Figure 2. Note how students simply need to locate information pertaining to each topic and category corresponding to the intersecting cells. Previous note taking research suggests learning advantages for students who take notes in a matrix as compared to students who take notes free form (see Kiewra (1991) for a review).

In particular, note taking research suggests that students who take matrix notes collect more information and achieve higher than do students who take free form notes (e.g., Igo, McCrudden, Bruning, \& Kauffman, 2003; Kauffman, Zhang, \& Yang, 2004; Kiewra et al., 1991). For example, Igo and colleagues (2003) found that students who took matrix notes collected significantly more information (experiment 1) and achieved higher on both free recall and on relationships tests (experiment 3) than free form note takers. Kauffman and his colleagues (2004)

\section{LEVELS OF MEASUREMENT}

Nominal: Purpose, Characteristics, Limitations, Examples

Ordinal: Purpose, Characteristics, Limitations, Examples

Interval: Purpose, Characteristics, Limitations, Examples

Ratio: Purpose, Characteristics, Limitations, Examples

Figure 1. Example freeform note taking tool. 


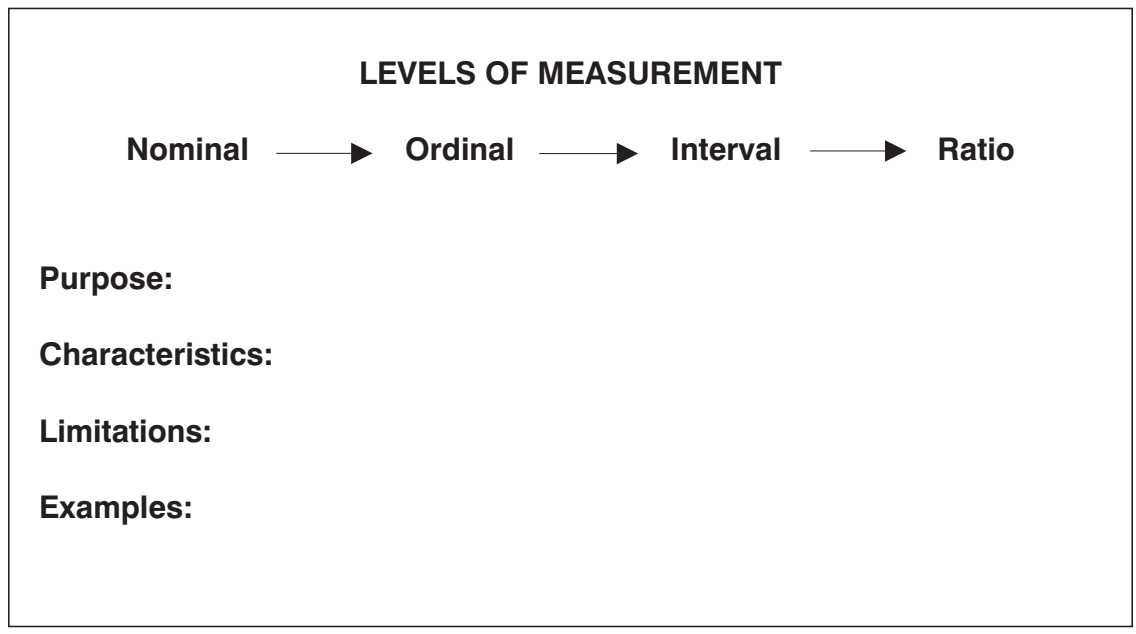

Figure 2. Example matrix note taking tool.

also found that matrix note takers collected more notes and achieved higher on both fact and relationship tests on a Web based note taking activity.

Based on these findings, it seems likely that by prompting students to take notes in a matrix, educators can improve students' note taking quality and increase achievement. Simply asking students to take notes using a matrix, however, may not be enough. Even when they possess high degrees of metacognitive awareness, students may still benefit from being reminded to select the most important information from the text.

\section{Metacognitive Component}

Self-regulated learning's metacognitive component refers to the knowledge and ability students have to regulate cognitive activities (Brown, 1987). These skills are unique from those falling within the cognitive component. Whereas cognitive processing includes skills that help learners carry out a specific task, metacognition includes skills that help learners understand and regulate these cognitive processes (Artzt \& Armour-Thomas, 1998).

There exists a large body of evidence suggesting that metacognitive processing is a hallmark of effective learning. Pressley and his colleagues (Van Etten, Pressley, \& Freebern, 1998; Van Meter, Yokoi, \& Pressley, 1994), for example, concluded that effective learners actively use metacognitive knowledge to manage their coursework.

The present study defined metacognition relative to self-monitoring; a student's awareness of their comprehension or performance during or shortly after 
completing an academic task (Nietfeld \& Schraw, 2002; Schraw \& Moshman, 1995). Self-monitoring is a critical aspect of effective SRL because it provides learners with self-generated feedback regarding their own performance (Butler \& Winne, 1995; Lan, 1998; Pintrich, Wolters, \& Baxter, 2000; Winne, 1996). Without self-monitoring, efficient control over one's cognitive system may be very limited.

Self-monitoring research generally measures existing self-monitoring processes and its influence on learning outcomes. For example, Schraw and his colleagues (Schraw, 1994; Schraw \& Nietfeld, 1998) examined college students' self-monitoring by asking students to make confidence judgments regarding their performance on specified tasks. These researchers have found positive relationships between self-monitoring and academic achievement. What this research rarely does, however, is investigate techniques designed to facilitate students' use of existing self-monitoring skills. Research investigating strategies for facilitating self-monitoring should provide educators with important information that can be used to improve students' SRL. Despite wide agreement that adults generally monitor their performance relatively accurately (e.g., Schraw \& Roedel, 1994; Tobias, 1995), research on prompting students to use existing metacognitive skills is rare.

One exception was a study examining how metacognitive prompting influenced students' performance on computer-simulated tasks (Veenman, Elshout, \& Busato, 1994). Students who received self-monitoring prompts not only recalled more information, but also were more systematic in their approach to completing tasks. The authors concluded that metacognitive prompting improves learning and thus deserves consideration as a strategy to improve instructional effectiveness.

Although research on metacognition and its components suggest learning advantages for students who monitor their progress, metacognition alone cannot explain why students choose to regulate their learning. In short, students must also possess the will to learn.

\section{Motivational Component}

Nearly every SRL model assumes motivation plays a significant role in students' academic success (e.g., Corno \& Mandinach, 1983; Pintrich \& Linnenbrink, 2000; Zimmerman, 1998). For example, most researchers assume self-regulated learners approach academic tasks with specific goals and possess high levels of self-efficacy (Horn et al., 1993; Pintrich \& Linnenbrink, 2000).

In the present study, the motivational component was operationally defined as academic self-efficacy which refers to students' judgments of their capabilities to organize and execute the course of action necessary to attain designated types of educational outcomes (Zimmerman, 1994). Previous research has identified academic self-efficacy as a significant predictor of student achievement (e.g., 
Horn et al., 1993; Pajares, 1996; Shell, Bruning, \& Colvin, 1989, 1995). Generally, students with high self-efficacy achieve higher than do students with lower self-efficacy (Bruning \& Horn, 2000; Shell et al., 1989, 1995).

There exists a large body of evidence suggesting that self-efficacy is influenced by students' previous experiences, which in turn, influences future achievement by increasing the likelihood that students successfully perform similar activities in the future (Bandura, 1997; Horn et al., 1993; Pajares, 1996). Based on this research, it seems likely that self-efficacy building feedback would have a positive influence on students' achievement.

Two studies by Schunk and his colleagues (Schunk \& Ertmer, 1999; Schunk \& Swartz, 1993) support the idea that feedback significantly influences students' efficacy judgments. In both studies, students received instruction and were prompted to pursue either process goals (e.g., "use these steps to write a paragraph") or product goals (e.g., "write a descriptive paragraph"). One half of the students also received efficacy-building feedback. Students who received feedback demonstrated higher achievement and increased self-efficacy judgments as compared to students who did not receive feedback. The authors concluded that academic achievement was influenced by students' self-efficacy judgments, particularly when those judgments were meditated by feedback students received from teachers about their performance.

\section{THE PRESENT STUDY}

The purpose of the present study is to investigate how Web-based instructional prompts influence note taking, self-monitoring, and self-efficacy, thereby influencing students SRL. Four predictions guide the present study. The SRL prediction is considered the primary prediction and the others are considered alternative predictions.

\section{SRL Prediction}

Matrix note takers will generate more organized notes and thus should be better able to take advantage of embedded self-monitoring prompts and selfefficacy building feedback. This prediction is supported by traditional SRL theory described above. Specifically, Winne (1995) argues that self-regulated learners monitor their strategies, while taking into account personal beliefs about competence in a particular domain.

\section{Self-Monitoring Prediction}

Students who take highly organized matrix notes should benefit more from self-monitoring prompts than students who take notes free form, particularly given the large amount of information offered in the Web-based instructional module. 


\section{Academic Self-Efficacy Prediction}

Students who take highly organized matrix notes will respond more to efficacy-building feedback than those who take less organized freeform notes.

\section{Note Taking Prediction}

Finally, students who take notes in a matrix organizer should collect more notes and achieve higher than students who take notes in a conventional free form method.

\section{METHOD}

\section{Participants and Design}

One hundred nineteen undergraduate students from a large Midwestern university were assigned randomly to one cell of a $2 \times 2 \times 2$ factorial design. Students were recruited from introductory Educational Psychology and Child Development courses as part of a class research requirement. Groups did not differ with respect to class standing, prior knowledge of educational psychology, psychology, statistics, and measurement. (See Table 1).

The first factor was note taking format. Students took notes either in a series of three matrix organizers or on three $81 / 2 \times 11$ sheets of paper. The second factor was presence or absence of self-monitoring prompts. Students either received or did not receive prompts designed to encourage self-monitoring of note taking. The third factor was presence or absence of academic self-efficacy building feedback. Students either received or did not receive feedback designed to bolster academic self-efficacy.

\section{Materials}

Materials included a pre-experimental survey designed to elicit demographic information and prior knowledge of educational measurement (the instructional topic), pre and post-experimental measures of academic self-efficacy and metacognitive awareness, a 3500 word text about educational measurement, two sets of note taking sheets corresponding to the experimental conditions, and three achievement tests. All materials were embedded in a Webquest ${ }^{\complement}$ created by the researcher.

\section{Pre-Experimental Questionnaire}

The demographic and prior knowledge questionnaires elicited information regarding students' gender $(1=$ male, $2=$ female $)$, class standing $(1=$ Freshman, $2=$ Sophomore, $3=$ Junior, $4=$ Senior, $5=$ Graduate student), grade-point average $(1=\mathrm{A}, 2=\mathrm{B}, 3=\mathrm{C}, 4=\mathrm{D}, 5=$ Other $)$, and academic major. The prior knowledge 
Table 1. Means (Standard Deviations) of Students' Demographic Information in Each Condition

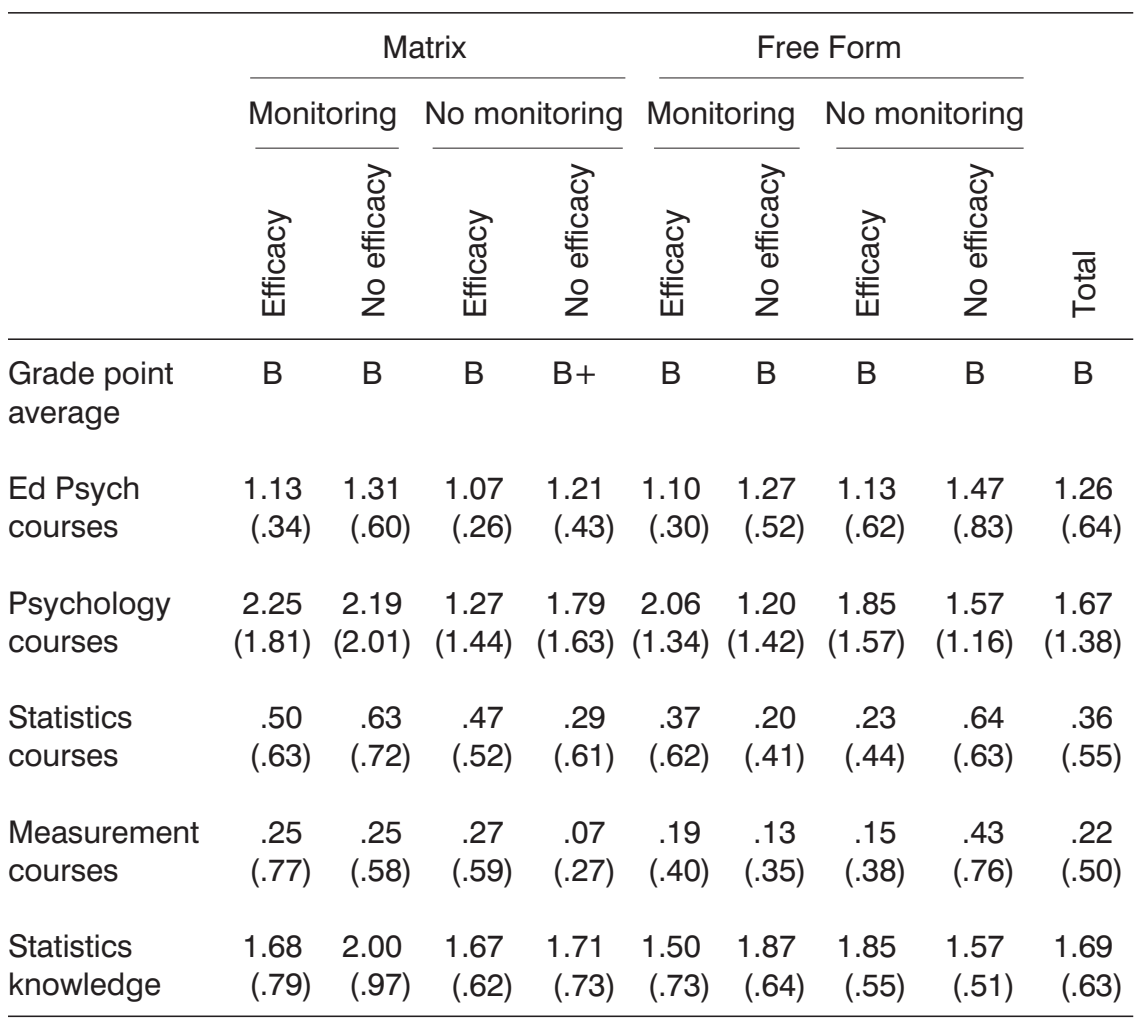

portion asked students the number of educational psychology, psychology, statistics, and measurement courses they have taken $(0-5+)$ as well as how much they knew about educational measurement and statistics $(1=$ next to nothing, $2=\mathrm{a}$ little, $3=\mathrm{a}$ fair amount, $4=\mathrm{a}$ great deal).

\section{Academic Self-Efficacy}

Academic self-efficacy was assessed with an eight-item instrument adapted from Lehman and colleagues ( $\alpha=.96)$ (Lehman et al., 2001). Students rated the likelihood of successfully completing various activities related to the learning task on a scale of zero (indicating no chance) to 100 (indicating complete certainty). For example, students were asked to rate how confident they are that "I can take notes that are useful for studying for the upcoming exam." The 
post-experimental efficacy inventory was identical to the pre-experimental measure, but was worded in the past tense.

\section{Metacognitive Awareness}

The Metacognitive Awareness Inventory (MAI) was adapted from a 52-item self-report instrument assessing students' metacognitive awareness (Schraw \& Sperling Dennison, 1994). In the present study, the MAI was divided into a 26-item form, equivalent to the original form $(\alpha=.91)$. The MAI assesses students' awareness of their knowledge and regulation of their cognition. Students responded to each item on a 100-point scale similar to the academic self-efficacy measure. The post-experimental MAI was identical to the pre-experimental measure, but was worded in the past tense.

\section{Learning Materials}

The learning materials included a 3532 word chapter on educational measurement adapted from Goetz, Alexander, and Ash (1992). A readability analysis revealed that the chapter was written at approximately a 10th grade reading level. The text was divided into three separate Web pages corresponding to the Levels of Measurement, Central Tendency and Dispersion, and Describing Scores in a Distribution sections.

The Levels of Measurement page organized 1043 words into four sub-sections corresponding to the four levels of measurement (nominal, ordinal, interval, and ratio). Each sub-section described the purpose, characteristics, examples, and limitations of the level of measurement described in that sub-section.

The Central Tendency and Dispersion Web page was divided 1590 words into two sections. The first section described the definition, level of measurement, calculation, and level of complexity of mean, median, and mode under the heading of Central Tendency. Next, the definition, level of measurement, calculation, and level of complexity of the range, variance, and standard deviation were described under the heading of dispersion.

Finally, the Describing Scores in a Distribution Web page contains 879 words and discussed the definition, level of measurement, calculation, examples, and major limitations of percentile rank, standard scores, and grade equivalents, in that order.

\section{Note Taking Sheets}

Two sets, corresponding to the matrix and free form note taking conditions, of three note taking sheets were constructed. In the matrix set, topic names appeared across the top row and categories were listed down the left-most column of a two-dimensional table (see Figure 2). The free form note taking sheet presented the identical topic and category information across the top rows of an otherwise 
blank $81 / 2 \times 11$ sheet of paper (see Figure 1). Sheet 1 corresponded to the Levels of Measurement Web site, sheet 2 was designed specifically for the Central Tendency and Dispersion Web page, and sheet 3 corresponded to the Describing Scores in a Distribution Web page. In all case, students were required to locate and note details corresponding to each topic and category from the three Web sites.

Learning Context

The learning materials were organized and presented on-line in a WebQuest ${ }^{\mathcal{C}}$. A WebQuest is an inquiry-based instructional tool designed to facilitate search and synthesis of information from multiple sources (Dodge, 1997).

WebQuest designers typically strive to make Web-based inquiry manageable by limiting to three or four the number of resources students must access and by supplying students with specific instructional goals (Brown-Yoder, 1999; Dodge, 1997). It typically contains six sections including an introduction, the task, the process, the resources, the evaluation procedures, and a conclusion (Brown-Yoder, 1999). The WebQuest designed for the present study was no exception.

The introduction linked the content, educational measurement, to activities common among classroom teachers. The task instructed students focus on important information cued by the note taking sheets. The process provided helpful hints or strategies for completing the task. Next, hyperlink to the resources - namely, three Web pages containing the content students were required to note. The evaluation and conclusion sections were combined into one section in which students were thanked for their participation, reminded that they would be asked to review their notes in preparation for three quizzes, and encouraged to incorporate what they gained from this exercise into their own professional development.

\section{Achievement Tests}

Three quizzes were developed to assess declarative, procedural, and application knowledge. These tests followed certain conventions used in previous note taking studies. The Declarative test was an 18-item multiple-choice test that assessed students' knowledge of specific facts presented in the Educational Measurement Web site $(\alpha=.74)$. An example declarative item is, "What measure of central tendency divides a set of scores?" The Procedural test was an eight-item supply test that asked students to calculate a number of basic statistics, such as standard deviation, described in the Educational Measurement Web site $(\alpha=.69)$. The Application test was a 15 -item fill-in-the-blank test that presented students with a series of "authentic" educational measurement issues $(\alpha=.71)$. For example, one Application test question was, "The variable, occupation, would be measured by which scale of measurement?" 


\section{Procedures}

The experiment was divided into five phases and occurred in groups of 8-12 students in a computer lab at the University. Upon arrival, students were instructed to sit at one of the computer terminals. All pencil and paper materials were organized in packets and stored in a folder located adjacent to students' keyboards.

During phase I, students were instructed to read through the materials located in the WebQuest's introduction, task, and process pages. Next, students completed the pre-experimental demographic, prior knowledge, academic selfefficacy, and metacognitive awareness questionnaires in that order.

Phase II was the note taking phase. Students were instructed to read and take notes on the information presented in the three "educational measurement"

Web pages. Students first accessed and noted information from the Levels of Measurement Web page, followed by Central Tendency and Dispersion and the Describing Scores in a Distribution Web pages, respectively.

Students in the self-monitoring condition were linked from each "Educational Measurement" Web page to Web pages containing self-monitoring prompts. These prompts asked students to make a confidence judgment about the completeness of their notes. An example of a self-monitoring prompt is, "Now would be a good time to ask yourself if you have collected all the important information. If you believe you can use your notes to answer the question below, then you are probably ready to move on to the next section. Otherwise, it would be a good idea to return to the Central Tendency and Dispersion page to complete your note taking." After responding to each self-monitoring prompt, students were linked to Web page containing a sample test question. For example, following the Levels of Measurement Web page, students were asked, "How are interval and ratio scales different?"

After answering the sample item, students in the efficacy-building condition were linked to a Web page containing statements designed to build their academic self-efficacy. Students who answered the sample item correctly were provided feedback such as, "Correct. This is very difficult item that only $24 \%$ of you classmates have gotten correct on the first try." This feedback is designed to build academic self-efficacy by comparing a student's performance with the performance of others.

Students who answered the item incorrectly were given feedback that they missed the item. They were told the item was difficult and were directed to try again. Once they answered the item correctly, these students were congratulated and then told, "your work is really paying off." This feedback is designed to build academic self-efficacy by comparing current performance with past performance. Once students in the efficacy-building condition have answered the item correctly and received their efficacy-building feedback, they were linked to the next note taking Web page and the sequence began again. 
Phase III occurred after the note taking phase and involved completing the post-experiment academic self-efficacy and metacognitive awareness questionnaires in that order. The post-experimental surveys were completed prior to achievement testing to minimize the likelihood that responses were based solely on studying behavior or on test performance.

Phase IV was the study phase. Students were given 15 minutes to review their notes "in preparation for three upcoming quizzes.

Finally, Phase V required students to complete the Declarative, Procedural, and Application tests in that order. Students were given as much time as they need on each test and were asked to do their best work. Students were asked to work only on the quiz that was currently being administered. On average, students took approximately 8 minutes to complete the Declarative test, 16 minutes to complete the Procedural test, and 14 minutes to complete the Application test. Following the phase $\mathrm{V}$ testing, students were thanked for their participation, debriefed, and dismissed.

\section{RESULTS}

Results are presented in two parts. Those assessing the fidelity of the treatment variables are presented first, followed by achievement-related results.

\section{Treatment Fidelity}

Prior to testing the hypotheses with respect to achievement, I sought to establish that the variables had the desired effects.

\section{Self-Efficacy Feedback}

To assess the influence of the self-efficacy feedback, a 2 (self-efficacy feedback) $\times 2$ (within subjects) ANOVA for scores on the pre- and post-experimental academic self-efficacy surveys was conducted. If the feedback had the desired effects, differences between pre- and post-experimental self-efficacy instrument should be observed for students who received it. Results revealed a significant within subjects $\times$ academic self -efficacy building feedback interaction, $F(1,115)=5.36, p<.05, M s \mathrm{e}=122.09$. Interestingly, students who received academic self-efficacy building feedback did not change their self-reported academic self-efficacy, whereas students who did not receive feedback increased their self-reported scores from pre- to post-experimental administrations. These somewhat surprising results suggest that receiving academic self-efficacy building feedback hindered students' beliefs in their capacity to succeed academically. It is possible that rather than hindering academic self-efficacy, the feedback improved accuracy of students' efficacy beliefs by providing students with an external assessment of their performance. 
Metacognitive Prompts

To establish that the self-monitoring prompts had the desired effects, a 2 (self-monitoring) $\times 2$ (within subjects) ANOVA was conducted for scores on the pre- and post-experimental Metacognitive Awareness Inventory (MAI). If the self-monitoring prompts cued students to monitor their progress, then changes should be seen for students who received prompts relative to those who did not. Results revealed a within subjects main effect for score on the MAI, $F(1,117)=$ 20.83, $p<.01, M s \mathrm{e}=10.97$, however no differences were observed between the two experimental groups. This indicated that the presence of self-monitoring prompts did not influence self-reported levels of metacognitive awareness.

\section{Note Taking Method}

Note taking was assessed by comparing the number of propositions gathered by students in the matrix and free form note taking conditions. Two independent raters analyzed students' notes by counting the number of propositions recorded. A proposition was defined as the smallest unit of information that can be judged true (Anderson, 1995; Kintch \& Van Dijk, 1978). One example in the present study is, "number assignment is arbitrary in nominal scales." To ensure that raters were consistent, an interrater reliability analysis was conducted. Each rater assessed a same sample of 25 sets of notes and the two ratings were compared. Results revealed strong agreement between raters for the number of propositions recorded $(\alpha=.89)$. A one way ANOVA revealed a main effect for note taking, $F(1,117)=32.54, p<.001, M s \mathrm{e}=41.63$. Students who took notes in matrices $(M=50.84)$ recorded more notes than did students who took notes in the free form method $(M=44.09)$.

\section{Achievement-Related Analyses}

A multivariate analysis of covariance (MANCOVA) was used to assess achievement-related results due to high intercorrelations among the achievement variables (see Table 2). Self-reported GPA, an index of student's previous academic success, was used as the covariate on this analysis. Next, I conducted between subjects analyses relative to each prediction.

\section{SRL Prediction}

The SRL prediction was a three-way interaction among note taking methods, self-monitoring prompts, and self-efficacy building feedback. Although the means appear consistent with a three-way interaction (see Table 3), results were not significant $(F<.34)$. Once it was established that no three-way interactions existed, the other predictions were investigated. 
Table 2. Zero-Order Correlations among Dependent Variables

\begin{tabular}{lccc}
\hline Dependent variable & 1 & 2 & 3 \\
\hline Declarative Quiz & $*$ & $.471^{*}$ & $.593^{*}$ \\
Procedural Quiz & $*$ & $*$ & $.415^{\star}$ \\
Application Quiz & $*$ & $*$ & $*$ \\
\hline$* p<.01$ & &
\end{tabular}

Table 3. Means (and Standard Deviations) for Scores on Each Test by Experimental Condition

\begin{tabular}{|c|c|c|c|c|c|c|c|c|}
\hline & \multicolumn{4}{|c|}{ Monitoring } & \multicolumn{4}{|c|}{ No monitoring } \\
\hline & \multicolumn{2}{|c|}{ Efficacy } & \multicolumn{2}{|c|}{ No efficacy } & \multicolumn{2}{|c|}{ Efficacy } & \multicolumn{2}{|c|}{ No efficacy } \\
\hline & $M$ & $(S D)$ & $M$ & $(S D)$ & $M$ & $(S D)$ & $M$ & $(S D)$ \\
\hline \multicolumn{9}{|l|}{ Matrix } \\
\hline Declarative & 15.31 & (1.66) & 14.81 & (1.83) & 14.27 & (1.49) & 13.07 & $(3.41)$ \\
\hline Procedural & 5.94 & (2.43) & 5.69 & (2.12) & 5.13 & (1.46) & 4.79 & $(1.76)$ \\
\hline Application & 12.38 & $(2.16)$ & 11.00 & $(2.76)$ & 10.47 & (3.23) & 8.29 & (3.67) \\
\hline \multicolumn{9}{|l|}{ Free Form } \\
\hline Declarative & 12.63 & (2.19) & 12.33 & (2.85) & 12.08 & (3.09) & 12.14 & $(2.85)$ \\
\hline Procedural & 4.63 & (2.09) & 4.47 & (1.60) & 4.31 & (1.49) & 4.57 & (1.65) \\
\hline Application & 9.50 & (2.66) & 9.53 & (2.70) & 8.62 & (3.01) & 8.71 & $(2.58)$ \\
\hline
\end{tabular}

\section{Self-Monitoring Prediction}

This prediction was that self-monitoring would interact with note taking method. Results revealed a significant main effect for self-monitoring prompts, $F(3,108)=3.34, p=.022$. Students who received self-monitoring prompts achieved higher as compared to students who did not receive prompts. A test of univariate effects revealed a significant self-monitoring $\mathrm{X}$ note taking interaction on the application test, $F(1,110)=4.36, p=.039, M s \mathrm{e}=7.34$. As seen in Table 3, matrix notetakers who received self-monitoring prompts $(M=11.69)$ achieved significantly higher on the application test than matrix notetakers who did not receive self-monitoring prompts $(M=9.41)$. In contrast, freeform notetakers who received self-monitoring prompts $(M=9.52)$ did not score significantly higher 
than freeform notetakers who did not receive self-monitoring prompts $(M=8.67)$. Finally, a main effect for self-monitoring was observed on the declarative test, $F(1,110)=3.99, p=.048, M S \mathrm{e}=5.48$. Students who received self-monitoring prompts $(M=13.73)$ achieved higher on the declarative test than did students who did not receive monitoring prompts $(M=12.31)$.

\section{Academic Self-Efficacy Prediction}

This prediction was that academic self-efficacy building feedback would interact with note taking methods. Results revealed no significant interactions or main effects relative to the presence of self-efficacy building statements. A test univariate effects, however, revealed a significant academic self-efficacy $\times$ note taking interaction on the application test, $F(1,110)=4.11, p=.045, M s \mathrm{e}=7.34$ $\left(\right.$ ETA $\left.^{2}=.04\right)$. As seen in Table 3, matrix notetakers who received self-efficacy building statements $(M=11.45)$ achieved higher on the application quiz than matrix notetakers who did not received efficacy-building statements $(M=9.73)$. In contrast, no differences were observed among freeform notetakers whether they received efficacy-building statements $(M=9.10)$ or not $(M=9.14)$.

\section{Note Taking Prediction}

The note taking prediction was that students who took notes in matrix organizers would record more notes and demonstrate superior performance on the three tests as compared to students who took free form notes. Results revealed a significant main effect for note taking methods, $F(3,108)=6.58, p<.001$. Students who took notes using the matrix achieved higher than students who took notes freeform.

A test of univariate effects revealed main effects for note taking on the Declarative test, $F(1,110)=19.30, p<.001, M s \mathrm{e}=5.48$. Students who took note in a matrix organizer $(M=14.41)$ achieved higher on the Declarative test than did students who took notes freeform $(M=12.31)$.

A main effect was also observed for note taking method on the Procedural test, $F(1,110)=6.14, p=.015, M s \mathrm{e}=3.52$. Students who took notes using the matrix method $(M=5.41)$ achieved higher than did students who took notes using the free form method $(M=4.50)$.

Finally, a main effect was observed for note taking method on the Application test, $F(1,110)=6.19, p=.014, M s \mathrm{e}=7.34$. Students who took notes using the matrix $(M=10.61)$ achieved higher than did students who took notes freeform $(M=9.12)$

\section{DISCUSSION}

The present study investigated interactions among note taking methods, selfmonitoring prompts, and academic self-efficacy building feedback within the 
context of a Web-based instructional module. This research is important for several reasons. First, the variables investigated here (cognitive, metacognitive, and motivational) represent fundamental components of SRL (Pintrich \& Linnenbrink, 2000; Schraw et al., 2002). What makes this study unique was that whereas most SRL research manipulates one or two variables, three variables were manipulated here. Hattie et al. (1996) noted that although these variables are related theoretically, there is a lack of empirical research investigating how metacognition and motivation influence study skill usage.

Second, this study was an opportunity to explore how specific cognitive, metacognitive, and motivational variables - namely, note taking, self-monitoring, and academic self-efficacy - influence how students regulate their learning in a Web-based setting. Future studies undoubtedly will need to explore each SRL component in different ways.

Third, the Web is a particularly relevant context given that students are increasingly required to interact with Web-based educational materials. The present study provided an ecologically valid context for exploring SRL in an environment that, by its very nature, requires students to be highly self-regulated.

The remainder of this discussion is divided into two parts relative to the four predictions that guided this study and to educational implications and directions for future research.

\section{Self-Regulated Learning Prediction}

The SRL prediction was a note taking method $\times$ self-efficacy building feedback $\times$ self-monitoring prompt interaction. Although means were consistent with respect to this prediction (see Table 3), results were not significant.

Although it is possible that these variables do not interact with each other, a more likely explanation relates to methodological limitations. Whereas students interacted with the note taking tool the entire hour they were completing the note taking activity, they received only one self-monitoring prompt and one self-efficacy building feedback statement for each Web site they visited (totaling three). It is likely students limited contact with the monitoring prompts and efficacy-building feedback, coupled with a relatively small sample size $(n=119)$, significantly influenced the sensitivity of the present study. Nevertheless, the pattern of means suggests effects not observed directly in this study. Certainly, future research should try to increase students' exposure to each component as well as increase the sample size,

\section{Self-Monitoring Prediction}

The self-monitoring prediction suggested an interaction between selfmonitoring prompts and note taking methods. This prediction was based on previous research suggesting it is easier for students to monitor organized information than it is to monitor less organized material (e.g., Ghatala, 1986). 
Accordingly, matrix note takers were predicted to benefit more from selfmonitoring prompts than were free form note takers.

Results revealed that students who received self-monitoring prompts achieved higher than did students who did not receive prompts. This is an important and promising result, particularly given that students were prompted to monitor their progress only three times in the course of one hour. Despite the relatively limited exposure, the prompts had a significant influence on achievement, suggesting there exist relatively simple approaches to implementing instructional strategies that positively influence students' self-monitoring and achievement in Web-based environments.

The univariate analyses further support the prediction that self-monitoring prompts can have a significant influence on students' achievement. First, the main effect for self-monitoring prompts on the Declarative quiz suggests that students who are prompted to monitor their progress can later recall discrete facts better than students who are not prompted to monitor. Additionally, the significant self-monitoring prompt by note taking methods interaction on the Application quiz suggests that prompting students to self-monitor has its greatest influence on students who study strategically. These findings are consistent with previous research that suggests self-monitoring has a significant influence on achievement, particularly when students are behaving strategically (e.g., Derry \& Murphy, 1986; Ghatala, 1986; Horn et al., 1993; Veenman et al., 1994).

Intuitively, it makes sense that students who were prompted to monitor would achieve higher, particularly on the application test, than students who were not prompted. Students who were prompted to check their notes and go back if necessary likely interacted more with their notes, and were thus more likely to develop a deeper understanding of how various educational measurement facts related to each other. Accordingly, they were better able to apply those facts to new situations.

\section{Academic Self-Efficacy Prediction}

This prediction involved an interaction between self-efficacy building feedback and note taking methods and was based on previous research indicating that motivation has its strongest influence on students who behave strategically (Bruning \& Horn, 2000; Horn et al., 1993; Pressley \& McCormick, 1995). Overall, results from the present study were mixed with respect to this prediction.

Unfortunately, results revealed no main effects or interactions involving the self-efficacy building feedback. This finding is inconsistent with previous research indicating that self-efficacy building feedback has a positive influence on students' achievement (e.g., Schunk \& Ertmer, 1999, Schunk \& Swartz, 1993).

The only significant result relative to this predication was a significant univariate self-efficacy building feedback by note taking method interaction on the Application quiz. Recall that the presence of efficacy-building statements 
had a significant influence on matrix notetakers, but had relatively little influence on the achievement of freeform notetakers. This is consistent with previous research indicating that self-efficacy has indirect influences on achievement through strategy use (Horn et al., 1993).

It is possible that the self-efficacy-building feedback simply had relatively little influence on students' achievement. Given the pattern of means and the significant univariate analysis on the Application quiz, however, a more likely explanation is that the efficacy-building feedback was not powerful enough and consequently the design of the study was not sensitive to achievement effects. Future research implementing this procedure will undoubtedly have to make a number of adjustments, including more and stronger efficacy-building feedback statements and a larger sample size.

\section{Note Taking Prediction}

This prediction was that students who took notes using the matrix note taking method would perform superior on achievement tests than would students who took notes using the freeform method. The rationale for this prediction was previous research indicating that students who take notes in matrix form collect more information and score higher on achievement tests than do students who take notes using a freeform note taking method (Kauffman et al., 2003; Kauffman $\&$ Kiewra, 1999). As predicted, students who took notes in a matrix organizer achieved higher than did students who took notes using the freeform method.

Results are consistent with previous research indicating that students who take (and/or study) matrix notes learn facts, procedures, and applications better than students who take (and/or study) free form notes. Kiewra and his colleagues (Kauffman \& Kiewra, 1999; Kiewra, Kauffman, Robinson, DuBois, \& Staley, 1999; Robinson \& Kiewra, 1995), for example, concluded that matrices facilitate learning better than text, in part, because matrices localize related information better than do text and outlines. Localization refers to how closely related information is placed on the printed page (Larkin \& Simon, 1987).

\section{Educational Implications}

Results presented here offer some important insights into the design and presentation of Web-based educational material. First, it appears that providing students with a matrix note taking tool is an efficient and effective way to help students gather and organize certain kinds of information (e.g., compare and contrast) from multiple Web sites.

A second implication relates to the use of academic self-efficacy building feedback. Results suggest that efficacy-building feedback has a positive influence on achievement, particularly on application-type questions. The technology involved in embedding efficacy-building statements could be extremely useful in Web-based environments. Previous research by Lehman and his colleagues 
(Lehman et al., 2001) suggests that on-line teachers often become overwhelmed by the number of e-mails they receive from students working in Web-based courses. The development of efficient Web-based tools, like those developed for the present study, can help minimize the pressure on-line teachers face by providing automated feedback designed to build academic self-efficacy.

Results from the present study also indicate that students who are prompted to monitor their progress achieve higher than do students who are not prompted to self-monitor. This is an important finding, particularly given that students received only three prompts. The present study suggests that simply asking students if they are certain, "they have gathered all the important information" and providing them with cues and opportunities to go back to improve their note taking are powerful instructional techniques that can be automated in Web-based settings.

\section{Future Directions}

The present study demonstrated that it is possible to experimentally manipulate cognitive strategy use, metacognitive processing, and motivational beliefs in a Web-based setting. Differences emerged among experimental groups, suggesting that carefully designed SRL prompts positively influence achievement. A number of theoretical and empirical questions remain.

First, results were inconclusive with respect to interactions among SRL's components. Although no significant results were observed, the pattern of means points to potential interactions among note taking method, academic self-efficacy building feedback, and self-monitoring prompts. It is possible that increased exposure to the self-monitoring and academic self-efficacy building prompts as well as larger sample sizes will allow future research in this area to pinpoint these interactions. Despite these limitations, some important differences emerged. More sensitive designs can only increase the statistical power this type of research has and consequently help researchers better understand each component's relative influence on academic achievement.

Second, future research should investigate how these components interact in various contexts. It is possible, for example, that these components will have varied influences in different settings. Whereas the cognitive component might play a primary role in a text-based context, self-monitoring might play a more prominent role in a multimedia context where students are asked to make decisions and are given choices regarding video and simulation presentations. Likewise, it would be interesting to explore each variable's influence under different achievement conditions. Writing, critical thinking, and problem solving activities may reveal different sets of results altogether.

Third, future research may want to modify the variables representing cognition, metacognition, and motivation. It may be helpful to alter one or two definitions at a time. For example, one future study could define the motivational component relative to attribution-building statements and the metacognitive 
component relative to self-evaluation prompts. Clearly, the interactions observed would vary with respect to how each component is defined.

Finally, it is absolutely critical that researchers continue to explore strategies educators can use to enhance students SRL in Web-based environments. At present, most SRL studies seem to focus on investigating relationships among various SRL components without exploring techniques for improving students' self-regulation. The present study has identified specific techniques educators can use to prompt students' self-regulation. As more studies are conducted in this area, we should be able to better to develop students' self regulated learning.

\section{ACKNOWLEDGMENTS}

I would like to thank Dr. Roger Bruning and Dr. Christy Horn at the Center for Instructional Innovation, Dr. Ken Kiewra at the University of Nebraska and Dr. Barbara Breene and Dr. Ray Miller at the University of Oklahoma for their invaluable assistance on earlier versions of this manuscript.

\section{REFERENCES}

Anderson, J. (1995). Learning and memory: An integrated approach. New York: John Wiley \& Sons Inc.

Artzt, A., \& Armour-Thomas, E. (1998). Mathematics teaching as problem solving: A framework for studying teacher metacognition underlying instructional practice in mathematics. Instructional Science, 26(1-2), 5-25.

Bandura, A. (1997). Self-efficacy: The exercise of control. New York: Freeman.

Bandura, A., Barbaranelli, C., Caprara, G., \& Pasterelli, C. (1996). Mechanisms of moral disengagement in the exercise of moral agency. Journal of Personality and Social Psychology, 71, 364-374.

Brown, A. (1987). Metacognition, executive control, self-regulation, and other mysterious mechanisms. In F. E. Weinert \& R. H. Kluwe (Eds.), Metacognition, Motivation, and Understanding. Hillside, NJ: Erlbaum.

Brown-Yoder, M. (1999). The Student WebQuest. Learning and Leading with Technology, 26, 6-9, 52-53.

Bruning, R., \& Horn, C. (2000). Developing motivation to write. Educational Psychologist, 35, 25-37.

Butler, D., \& Winne, P. (1995).Feedback and SRL: A theoretical synthesis. Review of Educational Research, 65, 245-281.

Corno, L., \& Mandinach, E. (1983). The role of cognitive engagement in classroom learning and motivation. Educational Psychologist, 18, 88-108.

Dodge, B. (1997). Some thoughts about webquests. Retrieved May 2000, from http://edweb.sdsu.edu/courses/edtec596/about_webquests.html.

Derry, S., \& Murphy, D. (1986). Designing systems that train learning ability: From theory to practice. Review of Educational Research, 56, 1-39. 
Du Bois, N., \& Staley, R. (1997). A self-regulated learning approach to teaching educational psychology. Educational Psychology Review, 9, 171-197.

Ghatala, E. (1986). Strategy-monitoring training enables young learners to select effective strategies. Educational Psychologist, 21, 43-54.

Goetz, E., Alexander, P., \& Ash, M. (1992). Educational psychology: A classroom perspective. New York: Merrill.

Hattie, J., Biggs, J., \& Purdie, N. (1996). Effects of learning skills interventions on student learning: A meta-analysis. Review of Educational Research, 66, 99-136.

Horn, C., Bruning, R., Schraw, G., \& Curry, E. (1993). Paths to success in the college classroom. Contemporary Educational Psychology, 18, 464-478.

Igo, B., McCrudden, R., Bruning, M., \& Kauffman, D. (2003). InfoGather: A Web-based tool for gathering and organizing Web-based information. In R. Bruning \& V. Horn (Eds.), Web-based learning: What do we know? Where do we go? Greenwich, CT: Information Age Publishing.

Kauffman, D., Zhang, G., \& Yang, Y. (2004). Supporting Web-based learning: Instructional tools designed to aid students' text search and achievement. Paper presented the 2004 Annual Meeting of the American Educational Research Association, San Diego, CA.

Kauffman, D., \& Kiewra, K. (1999). Indexing, extraction, and localization effects from learning form matrices, outlines, and text. Paper presented at the annual meeting of the American Educational Research Association, Montreal, Canada.

Kauffman, D., Lebow, R., Kiewra, K., \& Igo, L. (2000). All matrices are NOT created equal: How ordering matrix topics and categories affects learning. Invited presentation at the annual conference meeting of the American Educational Research Association, New Orleans, LA.

Kiewra, K. (1985). Investigating note taking and review: A depth of processing alternative. Educational Psychologist, 20, 25-32.

Kiewra, K. (1991). Aides to lecture learning. Educational Psychologist, 26, 37-53.

Kiewra, K., DuBois, N., Christian, D., McShane, A., Meyerhoffer, M., Roskelley, D. (1991). Note-taking functions and techniques. Journal of Educational Psychology, 83, 240-245.

Kiewra, K., Kauffman, D., Robinson, D., DuBois, N., \& Staley, R. (1999). Supplementing floundering text with adjunct displays. Instructional Science, 27, 373-401.

Kintch, W., \& Van Dijk, T. (1978). Toward a model of text comprehension and reproduction. Psychological Review, 85, 363-394.

Lan, W. (1998). Teaching self-monitoring skills in statistics. In D. H. Schunk \& B. J. Zimmerman (Eds.), SRL: From teaching to self-reflective practice (pp. 86-105). New York: Guilford.

Larkin, J., \& Simon, H. (1987). Why a diagram is (sometimes) worth ten thousand words. Cognitive Science, 11, 65-99.

Lehman, S., Kauffman, D., White, M., Horn, C., \& Bruning, R. (2001). Teacher interaction: Motivating at-risk students in Web-based high school courses. [online document] Journal of Research on Computing in Education, 33(5),

http://www.iste.org/jrte/33/5/lehman_s.html.

Nietfeld, J., \& Schraw, G. (2002). The effect of knowledge and strategy training on monitoring accuracy. Journal of Educational Research, 95(3), 131-142.

Pajares, F. (1996). Self-efficacy beliefs in academic settings. Review of Educational Research, 66, 543-578. 
Perry, N. (2002). Introduction: Using qualitative methods to enrich understandings of self-regulated learning. Educational Psychologist, 37, 1-5.

Pintrich, P. (2000). The role of goal orientation in SRL. In M. Boekaerts, P. Pintrich, \& M. Zeidner (Eds.), Handbook of self-regulation (pp. 452-501). San Diego, CA: Academic Press.

Pintrich, P., \& De Groot, E. (1990). Motivational and self-regulated learning components of classroom academic performance. Journal of Educational Psychology, 82, 33-40.

Pintrich, P., \& Linnenbrink, E. (2000). The role of motivation in intentional learning. Paper presented at the annual meeting of the American Educational Research Association, New Orleans, LA.

Pintrich, P., Wolters, C., \& Baxter, G. (2000). Assessing metacognition and selfregulated learning. In G. Schraw \& J. C. Impara (Eds.), Issues in the measurement of metacognition (pp. 43-97). Lincoln, NE: Buros Institute of Mental Measurements.

Pressley, M., \& McCormick, C. (1995). Cognition, teaching, and assessment. New York: HarperCollins.

Pressley, M., Woloshyn, V., Burkell, J., Cariglia-Bull, T., Lysynchuk, L., McGoldrick, J., Schneider, B., Snyder, B., \& Symons, S. (1995). Cognitive strategy instruction that REALLY improves children's academic performance (2nd ed.). Cambridge, MA: Brookline.

Robinson, D., \& Kiewra, K. (1995). Visual argument: Graphic organizers are superior to outlines in improving learning from text. Journal of Educational Psychology, 87, 455-467.

Schraw, G. (1994). The effect of metacognitive knowledge on local and global monitoring. Contemporary Educational Psychology, 19, 143-154.

Schraw, G., Kauffman, D., \& Lehman, S. (2002). SRL theory. In J. Levin (Ed.), Encyclopedia of cognitive science. London, England: Macmillan.

Schraw, G., \& Moshman, D. (1995). Metacognitive theories. Educational Psychology Review, 7, 351-371.

Schraw, G., \& Nietfeld, J. (1998). A further test of the general monitoring hypothesis. Journal of Educational Psychology, 90, 236-248.

Schraw, G., \& Roedel, T. (1994). Test difficulty and judgment bias. Memory \& Cognition, 22(1), 63-69.

Schraw, G., \& Sperling Dennison, R. (1994). Assessing metacognitive awareness. Contemporary Educational Psychology, 19, 460-475.

Schunk, D. H., \& Ertmer, P. (1999). Self-regulatory processes during computer skill acquisition: Goal and self-evaluative influences. Journal of Educational Psychology, 91, 251-260.

Schunk, D. H., \& Swartz, C. (1993). Goals and progress feedback: Effects on self-efficacy and writing achievement. Contemporary Educational Psychology, 18, 337-354.

Shell, D., Bruning, R., \& Colvin, C. (1989). Self-efficacy and outcome expectancy mechanisms in reading and writing achievement. Journal of Educational Psychology, $81,91-100$.

Shell, D., Bruning, R., \& Colvin, C. (1995). Self-efficacy, attribution, and outcome expectancy mechanisms in reading and writing achievement: Grade-level and achievement-level differences. Journal of Educational Psychology, 87, 386-398.

Tobias, S. (1995). Interest and metacognitive word knowledge. Journal of Educational Psychology, 87, 339-405. 
Van Etten, S., Pressley, M., \& Freebern, G. (1998). An interview study of college freshmens' beliefs about their academic motivation. European Journal of Educational Psychology, 13, 105-130.

Van Meter, P., Yokoi, L., \& Pressley, M. (1994). College students' theory of note taking derived from their perceptions of note-taking. Journal of Educational Psychology, 86, 323-338.

Veenman, M., Elshout, J., \& Busato, V. (1994). Metacognitive mediation in learning with computer-based simulations. Computers and Human Behavior, 10, 93-106.

Winne, P. (1996). A metacognitive view of individual differences in self-regulated learning. Learning and Individual Differences, 8, 327-353.

Winne, P. (1995). Inherent details in SRL. Educational Psychologist, 30, 173-187.

Zimmerman, B. J. (2000). Attaining self-regulated learning: A social-cognitive perspective. In M. Boekaerts, P. Pintrich, \& M. Zeidner (Eds.), Handbook of self-regulation (pp. 13-39). San Diego, CA: Academic Press.

Zimmerman, B. J. (1998). Academic studying and the development of personal skill: A self-regulatory perspective. Educational Psychologist, 33, 73-86.

Zimmerman, B. J. (1994). Dimensions of academic self-regulation: A conceptual framework for education. In D. H. Schunk \& B. J. Zimmerman (Eds.), Self-regulation of learning and performance: Issues and educational applications (pp. 3 -24). Hillside, NJ: Erlbaum.

Zimmerman, B. J. (1989). A social-cognitive view of self-regulated academic learning. Journal of Educational Psychology, 81, 329-339.

Direct reprint requests to:

Dr. Douglas Kauffman

University of Oklahoma

Dept. of Educational Psychology

820 Van Vleet Oval

Norman, OK 73019-2041

e-mail: dkauffman@ou.edu 